\title{
DETERMINAN ENTREPRENEURIAL INTENTION PADA MAHASISWA PERGURUAN TINGGI SWASTA (PTS) \\ DI JAKARTA BARAT
}

\author{
Tinjung Desy Nursanti, Masruroh, \& Laksmi Sito Dwi Irvianti \\ Fakultas Bisnis, Universitas Universitas Bina Nusantara \\ E-mail: tinjungdesy@yahoo.com
}

\begin{abstract}
ABSTRAK
Penelitian ini bertujuan untuk menganalisis faktor-faktor yang mempengaruhi keinginan untuk berwirausaha (intensi berwirausaha) bagi siswa yang telah memperoleh kursus kewirausahaan atau bahkan memilih kursus spesialisasi dalam kewirausahaan. Hal ini mengindikasikan bahwa ada tiga variabel yang mempengaruhi intensi berwirausaha, yaitu pendidikan program entreprenur, persepsi kelayakan dan persepsi keinginan. Analisis yang digunakan dalam penelitian ini adalah regresi berganda. Populasi penelitian ini adalah siswa di 3 PTS unggulan di wilayah Jakarta Barat. Hasil penelitian ini menunjukkan bahwa dari tiga variabel independen yang diusulkan, program pendidikan dan kelayakan yang dirasakan menunjukkan pengaruh positif tetapi tidak signifikan terhadap niat wirausaha. Sementara itu hanya ada satu variabel independen yang mempengaruhi niat kewirausahaan secara positif dan signifikan yang dirasakan keinginan.
\end{abstract}

Kata kunci: niat wirausaha, pendidikan wirausaha, kelayakan persepsi, keinginan perceived, kewirausahaan

\begin{abstract}
This study aims to analyze the factors that influence the desire for entrepreneurship (entrepreneurial intention) for students who have obtained courses in entrepreneurship or have even chosen specialization courses in entrepreneurship. It is indicated that there are three variables that influence entrepreneurial intention, namely entreprenur program education, perceived feasibility and perceived desirability. The analysis used in this study is multiple regression. The populations of this study are students in three excellent PTS in the West Jakarta area. The results of this study indicate that of the three independent variables proposed, educational programs and perceived feasibility show a positive but not significant effect on entrepreneurial intention. Meanwhile there is only one independent variable that influences entrepreneurial intention positively and significantly that is perceived desirability.
\end{abstract}

Keywords: entrepreneurial intention, entrepreneurial education, perceived feasibility, perceived desirability, entrepreneurship 


\section{Jurnal Manajemen Teori dan Terapan Tahun 12. No. 2, Agustus 2019}

\section{PENDAHULUAN}

Entrepreneurship secara universal diakui sebagai pilar perekonomian, faktor kunci untuk pengembangan usaha, penciptaan lapangan pekerjaan, dan pendorong pertumbuhan ekonomi. Keberadaan entrepreneurship merupakan solusi terbaik untuk mengatasi masalah perekonomian negara dalam rangka menjadikan sebuah negara menjadi negara maju (Nistorescu, 2011:251). Pada dasarnya, entrepreneurship merupakan bidang ilmu yang telah berkembang selama bertahun-tahun. Apabila seorang mahasiswa mampu untuk menjadi entrepreneur, maka hal ini diharapkan akan dapat menurunkan jumlah pengangguran yang ada di Indonesia serta akan menciptakan lapangan pekerjaan yang baru untuk masyarakat yang tidak memiliki pekerjaan.

Universitas merupakan salah satu agen yang berperan dalam menumbuhkan entrepreneurial intention, karena dari sinilah para mahasiswa dipersiapkan untuk menjadi seorang entrepreneur yang memang memiliki perceived feasibility dan perceived desirability untuk menjadi seorang entrepreneur menurut Hisrich, Peter dan Sheperd (2008) dalam Slamet, Tunjungsari dan Le (2014:3). Program pendidikan entrepreneurship harus merespon minat dan permintaan yang meningkat. Saat ini, program tersebut tampaknya berfokus pada penciptaan usaha baru yang didukung oleh opsi mengenai pertumbuhan bisnis, pembiayaan bisnis kewirausahaan, hukum, jaringan, bisnis keluarga dan perusahaan sosial dengan rencana bisnis memainkan peran sentral (Gibb, 2002). Beberapa studi yang telah dilakukan menunjukkan hasil bahwa program pendidikan entrepreneurship berkontribusi pada pengembangan entrepreneurial intention (Peterman \& Kennedy, 2003).

Berdasarkan point-point yang telah diuraikan di atas maka identifikasi masalah yang dapat dituliskan dalam penelitian ini adalah: Bagaimana pengaruh entrepreneurial education, perceived feasibility maupun perceived desirability terhadap entrepreneurial intention pada mahasiswa PTS di Jakarta Barat, baik secara parsial maupun secara simultan.

\section{TINJAUAN PUSTAKA}

Entrepreneurial intention dapat dilihat sebagai minat untuk menciptakan suatu organisasi baru atau sebagai perilaku pengambilan risiko dalam rangka memulai suatu bisnis baru (Thompson, 2009: 670). Penelitian yang telah dilakukan sehubungan pengaruh entrepreneurship education terhadap entrepreneurial intention antara lain dilakukan oleh Mumtaz et al., (2012) serta Turker dan Selcuk, (2009) dalam Ambad dan Damit (2015). Entrepreneurship education dapat dijadikan sebagai metode yang paling efisien dalam rangka melengkapi mahasiswa dengan 


\section{Tinjung Desy Nursanti \\ Masruroh \\ Laksmi Sito Dwi Irvianti}

pemahaman pengetahuan terkait entrepreneuship. Lebih lanjut, entrepreneurship education juga dapat mempengaruhi pilihan karir mahasiswa, seperti diterangkan oleh Peterman dan Kennedy (2003) dari hasil penelitiannya.

Sementara itu, entrepreneurial intention dapat dilihat sebagai minat untuk menciptakan suatu organisasi baru atau sebagai perilaku mengambil risiko untuk memulai suatu bisnis baru (Katz \& Gartner, 1988). Menurut Krueger dalam Drennan (2005) di universitas bisnis, mahasiswa menemukan bahwa entrepreneurial intention dapat disebabkan karena adanya keluarga mahasiswa yang melakukan bisnis (seperti orang tua memulai bisnis) mempunyai hubungan dengan perceived feasibility dan perceived desirability. Perceived desirability dijelaskan oleh Krueger (1993) sebagai "sejauh mana seseorang menemukan prospek memulai bisnis menjadi menarik; Intinya, ini mencerminkan affection seseorang terhadap kewirausahaan. "Kesediaan" semacam itu "untuk melakukan aktivitas entrepreneurial dapat dianggap sebagai kombinasi antara subjective norms dan Attitude toward the behaviour dalam model TPB. Shapero dan Sokol (1982) menguji konsep keinginan menggunakan data keluarga (terutama ayah atau ibu), kelompok sebaya, konteks pendidikan dan profesional dan nilai budaya yang dimiliki oleh calon pengusaha.

Perceived feasibility didefinisikan sebagai sejauh mana individu menganggap dirinya secara pribadi mampu melakukan aktivitas kewirausahaan. Perceived feasibility dapat dipengaruhi oleh adanya model peran atau mitra kerja, hambatan, dukungan finansial dan sosial, pendidikan, kepercayaan diri terhadap kemampuan seseorang untuk melakukan tugas entrepreneurial, atau melihat ketersediaan sumber daya yang dibutuhkan untuk menciptakan bisnis (Gasse dan Tremblay, 2011). Perceived feasibility dapat dilihat sesuai dengan baik dengan perceived behavioral control dalam model TPB Ajzen.

Mengingat Indonesia adalah salah satu negara dengan jumlah penduduk terbesar nomor empat di dunia, dapat dipastikan bahwa pemerintah secara umum akan menghadapi permasalahan ekonomi makro dalam penyediaan lepangan tenaga kerja seluas mungkin. Oleh karena itu, diharapkan konsep kewirausahaan dapat diperkenalkan sejak dini terhadap setiap individu terutama yang berada di jenjang sekolah formal, agar tidak terlalu tercipta mind-set untuk menjadi pencari kerja selepas lulus dari bangku kuliah. Sebaliknya, pola kewirausahaan dipupuk semenjak dini, agar individu lebih terbuka pikirannya untuk menciptakan sesuatu yang baru, yang ke depannya diharapkan justru dapat membuka lapangan pekerjaan bagi pihak 
lain yang lebih memerlukan. Oleh karena itu, pentingnya mata kuliah kewirausahaan ditekankan di perguruan tinggi adalah agar dapat dilakukan penyesuaian kurikulum dengan mata kuliah yang disampaikan, sehingga terwujud keselarasan bagi perguruan tinggi dan juga bagi negara di masa depan.

Atas dasar pemaparan yang telah disampaikan di atas, dapat digambarkan model penelitian yang dilakukan adalah sebagai berikut:

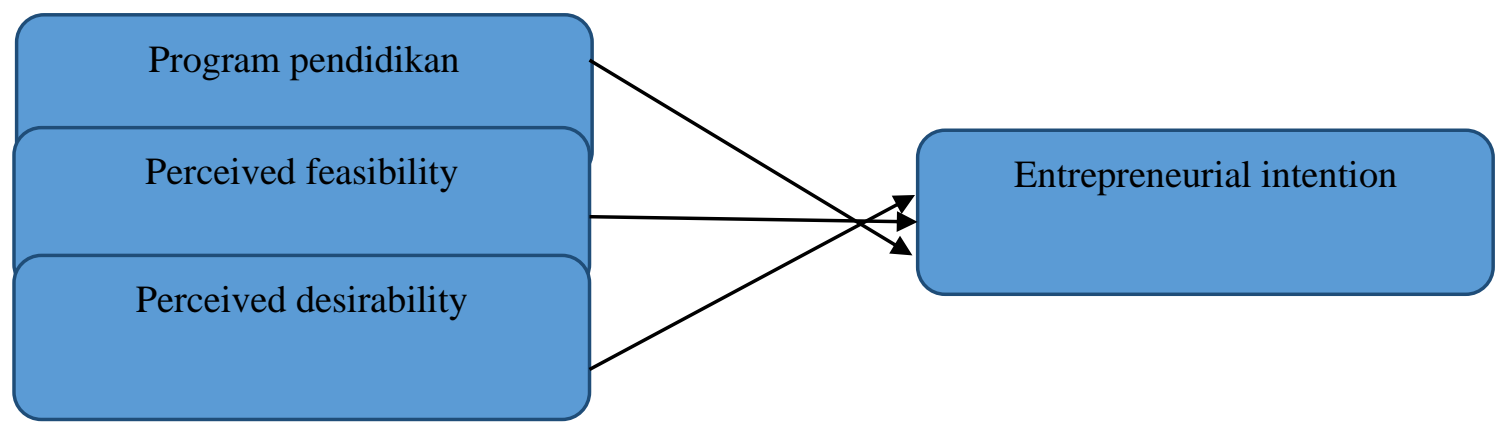

Gambar 2.1 Model Penelitian

Sumber: peneliti (2018)

\section{METODE PENELITIAN}

Penelitian ini menggunakan desain gabungan antara pendekatan kuantitatif dan kualitatif, di mana pendekatan kualitatif bermanfaat untuk mendukung pendekatan kuantitatif. Variabel penelitian ini terdiri dari:

1. Variabel Independen, meliputi variabel program pendidikan (PP), variabel perceived feasibility (PF) dan variabel perceived desirability (PD).

2. Variabel Dependen yaitu entrepreneurial intention (EI).

Sebagai subyek dalam penelitian ini diambil sample atau responden dalam penelitian ini yaitu mahasiswa di tiga PTS unggulan di wilayah Jakarta Barat. Teknik purposive sampling digunakan dalam penelitian ini, bahwa mahasiswa yang dijadikan responden penelitian adalah mereka yang diketahui telah mengambil mata kuliah entrepreneurship, komunikasi bisnis dan atau business plan karena secara umum ke tiga mata kuliah tersebut merupakan mata kuliah prasyarat yang wajib diambil mahasiswa yang berminat untuk mengambil peminatan entrepreneurial di fakultasnya. Mengingat keterbatasan waktu penelitian, akses perijinan yang memerlukan waktu, maka untuk memudahkan proses pengumpulan data, ditetapkan mahasiswa semester lima sebanyak 150 orang dengan menerapkan sampling convenience. Data dalam penelitian ini berupa data primer melalui penyebaran kuesioner kepada para mahasiswa yang menjadi responden penelitian serta data sekunder yang dikumpulkan melalui 


\section{Tinjung Desy Nursanti \\ Masruroh \\ Laksmi Sito Dwi Irvianti}

literatur jurnal maupun buku teks. Data yang telah terkumpul akan dianalisis dengan menggunakan bantuan SPSS untuk dapat mencapai tujuan penelitian. Adapun tahapan analisis data yang dilakukan meliputi uji validitas data dan uji reliabilitas data, kemudian dilanjutkan dengan uji asumsi klasik yang meliputi uji normalitas, multikolinieritas, serta heteroskedastisitas untuk mengetahui terpenuhi tidaknya asumsi klasik agar dapat dilanjutkan ke analisis berikutnya, yaitu analisis regresi berganda untuk mengetahui pengaruh dari masingmasing variabel independen terhadap variabel dependen, baik secara parsial maupun secara simultan.

\section{HASIL DAN PEMBAHASAN}

\section{Analisis Hasil Penelitian}

Uji validitas bertujuan untuk melihat ketepatan apakah data penelitian tidak berbeda dengan data sesungguhnya. Hasil pengolahan uji validitas untuk variabel program pendidikan, perceived feasibility, perceived desirability mahasiswa di tiga perguruan tinggi swasta di Jakarta Barat dinyatakan valid, kecuali butir pernyataan ke lima dari variabel perceived feasibility sehingga harus disisihkan dan tidak dapat dimasukkan untuk pengolahan lebih lanjut.

Uji reliabilitas bertujuan untuk melihat derajat konsistensi atau keandalan alat ukur data penelitian. Hasil pengolahan uji reliabilitas untuk variabel program pendidikan, perceived feasibility, perceived desirability dan entrepreneurial intention adalah dinyatakan andal apabila nilai Cronbach Alpha secara keseluruhan maupun bagi masing-masing butir pernyataan pada setiap variabel memiliki nilai lebih besar atau sama dengan $0.6(\geq 0.6)$. Adapun hasil reliabilitas secara keseluruhan menunjukkan bahwa seluruh butir pernyataan di setiap variable memiliki nilai memiliki nilai Cronbach Alpha 0.887 atau lebih besar atau sama dengan 0.6, yang artinya seluruh butir pernyataan dinyatakan reliabel.

Hasil pengujian berikutnya yaitu uji asumsi klasik menunjukkan seluruh residual data terdistribusi normal, memenuhi syarat tidak terjadi multikolinieritas dan tidak terjadi heteroskedastisitas, sehingga dapat dilanjutkan dengan analisis lebih lanjut. Dengan menggunakan one-sample Kolmogorov-Smirnov diketahui bahwa variabel program pendidikan, perceived feasibility, perceived desirability dan entrepreneurial intention terdistribusi normal. Nilai korelasi antar variabel independen < 0.8 menunjukkan bahwa tidak terdapat multikolinearitas. Sementara itu, dilihat dari perhitungan nilai tolerance dan VIF, yang kurang dari 10, dapat disimpulkan bahwa tidak terjadi multikolinieritas. Hasil pengolahan uji heteroskedastisitas dengan menggunakan uji 


\section{Jurnal Manajemen Teori dan Terapan \\ Tahun 12. No. 2, Agustus 2019}

Glejser untuk variabel program pendidikan, perceived feasibility dan perceived desirability menunjukkan bahwa tidak terjadi heteroskedastisitas.

\section{Analisis Regresi}

Setelah seluruh pengujian asumsi klasik selesai dilaksanakan dan seluruh asumsinya terpenuhi, tahap selanjutnya adalah melakukan uji regresi berganda. Analisis regresi linier berganda adalah analisis untuk mengetahui pengaruh dua atau lebih variabel independen (program pendidikan, perceived feasibility dan perceived desirability) terhadap variabel dependen yaitu entrepreneurial intention dan untuk memprediksi atau meramalkan arah hubungan suatu variabel dependen berdasarkan variabel independennya. Penelitian ini menggunakan persamaan regresi sebagai berikut:

$$
Y=a+b_{1} X_{1}+b_{2} X_{2}+b_{3} X_{3}
$$

Keterangan:
$\begin{array}{ll}\mathrm{Y} & =\text { Entrepreneurial intention } \\ \mathrm{a} & =\text { Koefisien prediktor } \\ \mathrm{b}_{1} \mathrm{~b}_{2} \mathrm{~b}_{3} & =\text { Koefisien regresi variabel independen } \\ \mathrm{X}_{1} & =\text { Program pendidikan } \\ \mathrm{X}_{2} & =\text { Perceived feasibility } \\ \mathrm{X}_{2} & =\text { Perceived desirability }\end{array}$

Analisis regresi linier berganda mencakup pengujian koefisien determinasi $\left(R^{2}\right)$, Uji statistik $t$, dan Uji statistik F. Hasil pengolahan uji regresi linier berganda untuk variabel program pendidikan, perceived feasibility dan perceived desirability terhadap entrepreneurial intention dapat dijelaskan sebagai berikut:

\section{Uji Koefisien Determinasi}

Koefisien determinasi menunjukkan seberapa besar kemampuan variabel independen (program pendidikan, perceived feasibility dan perceived desirability) mempengaruhi variabel dependen yaitu entrepreneurial intention. Hal itu dilakukan dengan mengacu pada besaran nilai adjusted $R$-square dari hasil analisis regresi, karena menggunakan persamaan regresi berganda yang dapat dilihat pada output model summary yang hasilnyapada tabel 1. 


\section{Tinjung Desy Nursanti \\ Masruroh \\ Laksmi Sito Dwi Irvianti}

Tabel 1.

Uji Koefisien Determinasi

\begin{tabular}{lcccc}
\hline \multicolumn{5}{c}{ Model Summary } \\
\hline Model & $R$ & R Square & $\begin{array}{c}\text { Adjusted R } \\
\text { Square }\end{array}$ & $\begin{array}{c}\text { Std. Error of } \\
\text { the Estimate }\end{array}$ \\
\hline 1 & $.695^{a}$ & .483 & .473 & 2.130 \\
\hline a. Predictors: (Constant), pd, pp, pf \\
\hline \multicolumn{4}{l}{ Sumber: Hasil Pengolahan } \\
\hline
\end{tabular}

Sumber: Hasil Pengolahan Data (2018)

Dari tabel 1 terkait hasil uji koefisien determinasi, dapat dilihat bahwa sebesar $47.3 \%$ entrepreneurial intention dipengaruhi oleh program pendidikan, perceived feasibility dan perceived desirability, sedangkan sisanya sebesar $52,7 \%$ dipengaruhi oleh faktor-faktor lain yang tidak dimasukkan dalam penelitian ini.

\section{Uji Anova}

Uji Anova atau uji F yaitu uji koefisien regresi secara bersama-sama untuk menguji signifikansi pengaruh beberapa variabel independen (dalam penelitian ini meliputi program pendidikan, perceived feasibility dan perceived desirability) terhadap variabel dependen (entrepreneurial intention). Menurut Priyatno (2014:186), kriteria pengujian pada uji Anova atau uji $F$ ini antara lain adalah sebagai berikut:

Hipotesis:

$\mathrm{H}_{0}$ : Tidak terdapat pengaruh signifikan program pendidikan, perceived feasibility dan perceived desirability terhadap entrepreneurial intention.

$\mathrm{H}_{\mathrm{a}}$ : Terdapat pengaruh signifikan program pendidikan, perceived feasibility dan perceived desirability terhadap entrepreneurial intention.

Kriteria pengujian pada uji Anova atau uji $\mathrm{F}$ berdasarkan signifikansi yang dapat digunakan sebagai dasar pengambilan keputusan adalah sebagai berikut:

Sig $\geq a(0,05)$, maka $\mathrm{H}_{0}$ diterima, tidak terdapat pengaruh signifikan.

Sig < a (0.05), maka Ho ditolak, terdapat pengaruh signifikan.

Keputusan :

$0,000<0,05$, maka Ho ditolak

Kesimpulan :

Berdasarkan table 2 berikut terkait uji anova hasil regresi berganda, dapat disimpulkan bahwa terdapat pengaruh signifikan program pendidikan, perceived feasibility dan perceived desirability terhadap entrepreneurial intention. 
Tabel 2.

Uji Anova Hasil Regresi Berganda

\begin{tabular}{|c|c|c|c|c|c|c|}
\hline \multicolumn{7}{|c|}{ ANOVAa } \\
\hline & Model & $\begin{array}{l}\text { Sum of } \\
\text { Squares }\end{array}$ & df & $\begin{array}{l}\text { Mean } \\
\text { Square }\end{array}$ & $\mathrm{F}$ & Sig. \\
\hline \multirow{3}{*}{1} & Regression & 619.937 & 3 & 206.646 & 45.544 & $.000^{b}$ \\
\hline & Residual & 662.436 & 146 & 4.537 & & \\
\hline & Total & 1282.373 & 149 & & & \\
\hline
\end{tabular}

a. Dependent Variable: ei

b. Predictors: (Constant), pd, pp, pf

Sumber: Hasil Pengolahan Data (2018)

Tabel 3.

Persamaan Regresi Linear Berganda

\begin{tabular}{|c|c|c|c|c|c|c|}
\hline \multicolumn{7}{|c|}{ Coefficients ${ }^{a}$} \\
\hline \multirow{2}{*}{\multicolumn{2}{|c|}{ Model }} & \multicolumn{2}{|c|}{$\begin{array}{c}\text { Unstandardized } \\
\text { Coefficients }\end{array}$} & \multirow{2}{*}{$\begin{array}{c}\text { Standardized } \\
\text { Coefficients } \\
\text { Beta }\end{array}$} & \multirow[t]{2}{*}{$t$} & \multirow[t]{2}{*}{ Sig. } \\
\hline & & $B$ & Std. Error & & & \\
\hline \multirow{4}{*}{1} & (Constant) & 2.885 & 1.855 & & 1.555 & .122 \\
\hline & $\mathrm{Pp}$ & .081 & .051 & .109 & 1.599 & .112 \\
\hline & $\mathrm{Pf}$ & .061 & .053 & .080 & 1.153 & .251 \\
\hline & $\mathrm{Pd}$ & 1.039 & .110 & .614 & 9.425 & .000 \\
\hline
\end{tabular}

a. Dependent Variable: ei

Sumber: Hasil Pengolahan Data (2018)

Persamaan regresi berganda yang dapat dituliskan dari hasil perhitungan pada tabel coefficient di atas adalah sebagai berikut:

\section{$Y=2.885+0.081 \times 1+0.061 \times 2+1.039 \times 3$}

Hasil persamaan regresi berganda di atas, dapat diinterpretasikan sebagai berikut:

1. Jika $X_{1}$ (program pendidikan), $X_{2}$ (perceived feasibility), dan $X_{3}$ (perceived desirability) tetap (konstan), maka rata-rata $Y$ (entrepreneurial intention) akan sebesar 2.885 point.

2. Jika $X_{1}$ (program pendidikan) naik sebesar 1 point maka rata-rata $Y$ (entrepreneurial intention) akan mengalami kenaikan sebesar 0.081 point dengan asumsi perceived feasibility $\left(\mathrm{X}_{2}\right)$ dan perceived desirability $\left(\mathrm{X}_{3}\right)$ konstan.

3. Jika $X_{2}$ (perceived feasibility) naik sebesar 1 point maka rata-rata $Y$ (entrepreneurial intention) akan mengalami kenaikan sebesar 0.061 point dengan asumsi program pendidikan $\left(X_{1}\right)$ dan perceived desirability $\left(X_{3}\right)$ konstan.

4. Jika $X_{3}$ (perceived desirability) naik sebesar 1 point maka rata-rata $Y$ (entrepreneurial intention) akan mengalami kenaikan sebesar 1.039 point dengan asumsi program pendidikan $\left(X_{1}\right)$ dan perceived feasibility $\left(X_{2}\right)$ konstan. 


\section{Tinjung Desy Nursanti \\ Masruroh \\ Laksmi Sito Dwi Irvianti}

Analisis berikutnya adalah melakukan uji † untuk mengetahui pengaruh parsial masing-masing variabel independen (program pendidikan, perceived feasibility dan perceived desirability) terhadap variabel dependen (entrepreneurial intention) dengan mengacu pada nilai signifikansi masing-masing variabel independen yang tertera pada tabel 3.

\section{Uji $†$}

1. Pengaruh parsial $X_{1}$ (program pendidikan) terhadap $Y$ (entrepreneurial intention)

Adapun hipotesa penelitian adalah sebagai berikut:

$\mathrm{H}_{0}$ : Tidak terdapat pengaruh signifikan program pendidikan terhadap entrepreneurial intention.

$\mathrm{H}_{\mathrm{a}}$ : Terdapat pengaruh signifikan program pendidikan terhadap entrepreneurial intention.

Kriteria pengujian pada uji $\dagger$ atau uji parsial berdasarkan signifikansi yang dapat digunakan sebagai dasar pengambilan keputusan adalah sebagai berikut:

Sig $\geq a(0,05)$, maka $\mathrm{H}_{0}$ diterima, tidak terdapat pengaruh signifikan.

Sig < a (0.05), maka $\mathrm{H}_{0}$ ditolak, terdapat pengaruh signifikan.

Keputusan:

$0,112>0,05$, maka $\mathrm{H}_{0}$ diterima

Kesimpulan:

Dari tabel 3 dengan mengacu pada nilai signifikansi yang ada dapat disimpulkan bahwa tidak terdapat pengaruh signifikan secara parsial program pendidikan terhadap entrepreneurial intention.

2. Pengaruh parsial $X_{2}$ (perceived feasibility) terhadap $Y$ (entrepreneurial intention)

Adapun hipotesa penelitian adalah sebagai berikut:

Ho: Tidak terdapat pengaruh signifikan perceived feasibility $\left(X_{2}\right)$ terhadap entrepreneurial intention.

$\mathrm{H}_{\mathrm{a}}$ : Terdapat pengaruh signifikan perceived feasibility $\left(\mathrm{X}_{2}\right)$ terhadap entrepreneurial intention.

Kriteria pengujian pada uji † atau uji parsial berdasarkan signifikansi yang dapat digunakan sebagai dasar pengambilan keputusan adalah sebagai berikut:

Sig $\geq a(0,05)$, maka $\mathrm{H}_{0}$ diterima, tidak terdapat pengaruh signifikan.

Sig < a (0.05), maka Ho ditolak, terdapat pengaruh signifikan.

Keputusan: 
$0,251>0,05$, maka $\mathrm{H}_{0}$ ditolak

Kesimpulan :

Dari tabel 3 dengan mengacu pada nilai signifikansi yang ada dapat disimpulkan bahwa tidak terdapat pengaruh signifikan secara parsial perceived feasibility terhadap entrepreneurial intention.

3. Pengaruh parsial $X_{3}$ (perceived desirability) terhadap $Y$ (entrepreneurial intention)

Adapun hipotesa penelitian adalah sebagai berikut:

Ho: Tidak terdapat pengaruh signifikan perceived desirability terhadap entrepreneurial intention.

Ha: Terdapat pengaruh signifikan perceived desirability terhadap entrepreneurial intention.

Kriteria pengujian pada uji $\dagger$ atau uji parsial berdasarkan signifikansi yang dapat digunakan sebagai dasar pengambilan keputusan adalah sebagai berikut:

Sig $\geq a(0,05)$, maka $\mathrm{H}_{0}$ diterima, tidak terdapat pengaruh signifikan.

Sig < a (0.05), maka Ho ditolak, terdapat pengaruh signifikan.

Keputusan :

$0,000<0,05$, maka $\mathrm{H}_{0}$ ditolak

Kesimpulan:

Dari tabel 3 dengan mengacu pada nilai signifikansi yang ada dapat disimpulkan bahwa secara parsial terdapat pengaruh signifikan perceived desirability terhadap entrepreneurial intention.

\section{Implikasi Penelitian}

Berdasarkan hasil analisis data penelitian, maka diperoleh hasil implikasi penelitian sebagai berikut:

1. Hasil pengolahan data terkait pengaruh variabel program pendidikan terhadap entrepreneurial intention mahasiswa di tiga PTS di Jakarta Barat menunjukkan bahwa program pendidikan mempengaruhi entrepreneurial intention secara positif meskipun tidak signifikan. Hal ini diperkirakan karena sampel responden yang dituju adalah perguruan tinggi swasta yang dua di antaranya tidak memiliki program khusus dalam mengembangkan kewirausahaan di dalamnya, melainkan sebagai pelengkap atas mata kuliah yang harus diambil saja. Mahasiswa memang mengambil peminatan entrepreneurship, tetapi PTS tersebut adalah PTS umum dengan beragam program studi yang ditawarkan. 


\section{Tinjung Desy Nursanti \\ Masruroh \\ Laksmi Sito Dwi Irvianti}

2. Hasil pengolahan data terkait pengaruh variabel perceived feasibility terhadap entrepreneurial intention mahasiswa di tiga PTS di Jakarta Barat menunjukkan bahwa perceived feasibility mempengaruhi entrepreneurial intention secara positif tetapi juga tidak signifikan. Padahal perceived feasibility menunjukkan karakteristik seseorang yang mendapatkan dukungan langsung dari keluarga dalam menjalankan usahanya dari awal atau dikenal juga sebagai faktor keturunan, sementara dalam penelitian ini hasilnya menunjukkan pengaruh yang tidak signifikan,

3. Hasil pengolahan data terkait pengaruh variabel perceived desirability terhadap entrepreneurial intention mahasiswa di tiga PTS di Jakarta Barat menunjukkan bahwa variable perceived desirability merupakan satu-satunya variabel yang mempengaruhi entrepreneurial intention secara positif dan signifikan. Hal ini diperkirakan karena karakteristik mahasiswa milenial sendiri yang melatarbelakangi bahwa keinginan atau hasrat yang sangat kuat yang muncul dari dalam diri mereka sendirilah yang mempengaruhi entrepreneurial intention.

\section{SIMPULAN}

Program pendidikan berpengaruh secara positif terhadap entrepreneurial intention mahasiswa di tiga perguruan tinggi swasta di Jakarta Barat, tetapi pengaruhnya tidak signifikan. Perceived feasibility berpengaruh secara positif terhadap entrepreneurial intention mahasiswa di tiga perguruan tinggi swasta di Jakarta Barat, tetapi pengaruhnya juga tidak signifikan. Perceived desirability berpengaruh secara positif terhadap entrepreneurial intention mahasiswa di tiga perguruan tinggi swasta di Jakarta Barat, dan pengaruhnya signifikan. Secara bersama-sama, ketiga variabel independen dalam penelitian ini yaitu variabel program pendidikan, variabel perceived feasibility dan variabel perceived desirability mempengaruhi entrepreneurial intention mahasiswa di tiga perguruan tinggi swasta di Jakarta Barat.

\section{REFERENSI}

Ambad, S. N. A., dan Damit, D. H. D. A. 2016. Determinants of Entrepreneurial Intention among Undergraduate Students in Malaysia, Fifth International Conference On Marketing And Retailing (5TH INCOMaR) 2015. Procedia Economics and Finance 37: 108 - 114.

Drennan, J., Kennedy, J., dan Renfrow, P. 2005. Impact of Childhood Experiences on the Development of Entreprenurial Intentions. Entrepreneurship and Innovation: 231-238.

Gasse, Y., dan Tremblay, M. 2011. Entreprenurial Beliefs and Intentions: A Cross-Cultural Study of University Students in Seven Countries. International Journal of Business 16 (4): 304-314. 


\section{Jurnal Manajemen Teori dan Terapan Tahun 12. No. 2, Agustus 2019}

Gibb, J. 2002. The Collection of Research Reading on Generic Skill in VET (online). Tersedia: http://www.ncvr.edu.au.hotm. [17 Nopember 2008].

Katz, J., dan Gartner, W. B. 1988. Properties of Emerging Organizations. Academy of Management Review 13 (3).

Krueger, N., \& Carsrud, A. 1993. Entrepreneurial Intentions; Applying the Theory of Planned Behaviour. Entrepreneurship \& Regional Development 5-4: 315-330.

Mumtaz, B. A. K., Munirah, S., dan Halimahton, K. 2012. The Relatioship between Educational Support and Entreprenurial Intentions in Malaysian Higher Learning Institutions. ProcediaSocial and Behavioural Sciences, vol. 69 (24): 2164-2173.

Nistorescu, T. D. 2015. Determinants of Entrepreneurial Intent of Student in Oltenia Region. Review of International Comparative 12 (2).

Peterman, N. E. dan Kennedy, J. 2003. Enterprise education: Influencing students'perceptions of entrepreneurship. Entrepreneurship Theory and Practice 28 (2): 129-144.

Priyatno, D. 2014. SPSS 22 Pengolahan Data Terpraktis. Yogyakarta: CV Andi Offset.

Shapero, A., dan Sokol, L. 1982. The social dimensions of entrepreneurship. In C. Kent, D. Sexton and K. Vesper (Eds.) Encyclopaedia of Entrepreneurship: 72-90.

Slamet, F., Tunjungsari, H. K., dan Mei, L. 2016. Dasar- Dasar Kewirausahaan: Teori dan Praktek. Jakarta Barat: PT Indeks.

Thompson, E. R. 2009. Individual Entrepreneurial Intent: Construct Clarification and Development of an Internationally Reliable Metric. Entrepreneurship: Theory and Practices 33 (3): 669694. 